\title{
Erratum to: Submarine Geomorphology
}

\author{
Aaron Micallef, Sebastian Krastel and Alessandra Savini
}

\section{Erratum to:}

\section{A. Micallef et al. (eds.), Submarine Geomorphology, Springer Geology, https://doi.org/10.1007/978-3-319-57852-1}

The original version of the book was inadvertently published with the following errors, which have been now corrected:

In Chapter "Oceanic Trenches", the overlapped Fig. 5 has been corrected.

In Chapter "Cold-Water Carbonate Bioconstructions" the reference "Guinan et al. (2000)" has been changed to read as "Guinan et al. (2009)" in the reference list and citation, which is a belated correction.

In Chapter "National Programmes: Geomorphological Mapping at Multiple Scales for Multiple Purposes", Figs. 1, 3 and 4 have been replaced correctly.

The erratum book has been updated with the changes.

The updated original online version of this book can be found at https://doi.org/10.1007/978-3-319-57852-1 